\title{
Can We Make School Mathematics Work for All?
}

\author{
Lynn Arthur Steen
}

\begin{abstract}
This is a revised text of a paper presented under the title "Reflections on Mathematics and Democracy" at a joint AMS-MAA Special Session at MathFest 2012 in Madison, Wisconsin. The session was organized by David Mumford and Solomon Garfunkel; other speakers were William McCallum, Hyman Bass, and Joseph Malkevitch.
\end{abstract}

This Special Session was organized to discuss two pressing questions facing the mathematics community:

- What mathematics should every citizen know?

- How should K-16 education get us there? The original motivation was an op-ed in the New York Times ${ }^{1}$ that proposed a rather unorthodox answer to the second question, namely, to arrange high school mathematics into mathematically rich applied courses in which the desired mathematical skills and knowledge would emerge within realistic contexts.

As if on cue, one week prior to this session CUNY political scientist Andrew Hacker made a similar argument, also in the Times. ${ }^{2}$ Although the headline on his op-ed, "Is Algebra Necessary?", makes it appear as if Hacker is arguing that algebra is not important, what he really says is that it is not working in the curriculum: "Something other than algebra is needed to enhance students'

Lynn Arthur Steen is professor emeritus of mathematics at St. Olaf College and a former president of the MAA. His email address is steen@stolaf.edu.

${ }^{1}$ David Mumford and Sol Garfunkel, "How to Fix Our Math Education,"New York Times, August 24, 2011, www. nytimes.com/2011/08/25/opinion/how-to-fixour-math-education.htm1.

${ }^{2}$ Andrew Hacker, "Is Algebra Necessary?", New York Times, July 29, 2012, www . nytimes.com/2012/07/29/opinion/ sunday/is-algebra-necessary.htm1?pagewanted= a17.

DOI: http://dx.doi.org/10.1090/noti1062 understanding of where various numbers come from and what they actually convey."

Today we are at the cusp of a twenty-five-year effort to develop a common set of standards for school mathematics (and other subjects). Not surprisingly, these proposed "Common Core" standards ${ }^{3}$ improve on rather than overthrow orthodoxy. They generally adhere to the traditional curriculum, especially in their emphasis on algebra, while also encouraging limited innovation.

Ten years ago I addressed the first question posed to this panel in Mathematics and Democracy, a collection of essays from a variety of professionals both inside and outside mathematics. ${ }^{4}$ (These essays are available for free downloading on the MAA website.) The chief message of this volume is that the mathematics taught in school bears little relationship to the mathematics needed for active citizenship. That mathematics we called quantitative literacy (QL) to contrast it with traditional school mathematics, which, historically, was the mathematics students needed to prepare for calculus.

Mathematics and quantitative literacy are distinct but overlapping domains. Whereas mathematics' power derives from its generality and abstraction, QL is anchored in specific contexts and real-world data. An alternative framing of the challenge for this panel is to ask whether perhaps QL might be a more effective approach to high school mathematics for all.

$$
* * * * *
$$

The disconnect of school mathematics from lives of citizens is not a new complaint. Twenty years ago the late Washington Post columnist William Raspberry stirred up a tempest by arguing

\footnotetext{
${ }^{3}$ Common Core Standards: Mathematics, www corestandards.org/the-standards/mathematics/.

${ }^{4}$ Lynn Arthur Steen, editor, Mathematics and Democracy: The Case for Quantitative Literacy, National Council on Education and the Disciplines, Princeton, 2001, www. maa. org/q1/mathanddemocracy.htm1.
} 
that for many students much of high school mathematics was little more than an unnecessary impediment: "It is a mistake to suppose that requiring the nonmathematical to take more advanced math courses will enhance their understanding, and not merely exacerbate their sense of inadequacy."

Because it dominates high school mathematics, algebra is clearly the lightning rod for general complaints about school mathematics. A recent op-ed in USA Today challenged the "endemic" pressure to have younger and younger children take algebra, describing as a "canard" the misplaced belief that algebra is essential to the future success of thirteen- or fourteen-year-olds. ${ }^{6}$

Even NCTM past president Michael Shaughnessy has voiced concerns about "endless algebra" creating a "misguided" and "deadly" pathway from high school to college mathematics. ${ }^{7}$ He cites a recent report by an MAA committee that studied the mathematical needs of client disciplines: it calls for a greater emphasis on modeling (including units, scaling, and dimensional analysis), multivariate topics, and computational skills that are useful in other fields. ${ }^{8}$

A large number of average Americans share the unease expressed by these columnists. Of course, a large number disagree, including, I suspect, a majority of mathematicians. Critics worry that diminishing the centrality of algebra in high school is tantamount to giving up on mathematics. For example, MAA past president David Bressoud, while agreeing that the "singular view" of high school mathematics as preparation for calculus is "a serious mistake," nonetheless argues that easing up on algebra "would lead to a variety of soft options in high school" that preclude further study of mathematics in college. ${ }^{9}$

$$
* * * * *
$$

So we are faced with two competing "shoulds": either improve algebra or offer something other than algebra. For a reality check, consider how

\footnotetext{
${ }^{5}$ William Raspberry, "Math Isn't for Everyone”, Washington Post, 1989, A23.

${ }^{6}$ Patrick Welsh, "Why Our Kids Hate Math", USA Today, July 9, 2012,http://www.usatoday.com/news/opinion/ forum/story/2012-07-09/math-education-remedia1algebra/56118128/1.

${ }^{7}$ J. Michael Shaughnessy, "Endless Algebra-The Deadly Pathway from High School Mathematics to College Mathematics", NCTM Summing Up, February 2011, www . nctm. org/about/content . aspx?id=182.

${ }^{8}$ Partner Discipline Recommendations for Introductory College Mathematics and the Implications for College Algebra, Mathematical Assoc. of Amer., 2011, http:// www.maa.org/cupm/crafty/introreport.pdf.

${ }^{9}$ David Bressoud, “The End of Algebra?", Launchings, Mathematical Assoc. of Amer., March 2011, maa.org/ columns/launchings/launchings_03_11.htmp.
}

these options relate to the "is" of U.S. math education.

As is widely known, the U.S. consistently trails other nations in international tests (although both the significance and relevance of this finding is widely disputed). Perhaps more relevant-and I think more disturbing-is evidence spanning the last twenty-five to thirty years showing that increased enrollment in high school mathematics does not lead to increased learning of mathematics-at least not in proportion to the effort invested.

Specifically, society's emphasis on STEM education has caused enrollments in high school mathematics to soar, especially in upper division courses, which have more than doubled in relation to the population of students. Yet indicators of learning have hardly changed: scores on the twelfth-grade NAEP mathematics test are only slightly higher than three decades ago. More tellingly, the proportion of students requiring remedial courses in college has remained more or less the same for the last thirty years at about 30-35 percent.

Hacker cites other evidence in his Times op-ed. For example, one in four high school students fails to graduate on time, and failure to pass algebra is one of the key reasons for this failure.

Among students who do pass Algebra I and stay enrolled in mathematics, many still fail required high school exit exams, a relatively new fad growing out of the standards and accountability movement. This year thousands of Minnesota high school seniors "repeatedly failed" the statemandated mathematics test and were able to graduate only because of waivers granted by the state department of education. ${ }^{10}$ Similar problems are arising in many other states.

(As it happens, Minnesota is one of only five states that have declined to sign onto the Common Core mathematics standards on the grounds that their own standards are "higher and more rigorous." It seems that there is a big difference between setting and achieving high standards.)

For whatever reason, the mathematics students learn in school is a pale shadow both of what they were taught and of what the various standards recommend. One result is a cascade of difficulties when these students arrive in college. A large proportion of college students drop out before completing their intended degree or certificate, and many blame college math requirements. As evidence, Hacker cites two studies: (i) a CUNY faculty report on student retention that concluded, "failing math at all levels affects retention more

\footnotetext{
${ }^{10}$ Christopher Magan, "Many Students Fail Math grad Exam-But Still Graduate", Pioneer Press, July 24, 2012, http://www . twincities.com/1ocalnews/ ci_21122870/minnesota-many-students-fai1math-grad-exam-but
} 
than any other academic factor" and (ii) a national sample of transcripts that showed that mathematics gave twice as many F's and D's as did other subjects.

$$
* * * * *
$$

So we have a dilemma. The traditional high school mathematics curriculum, which was designed for and is still necessary for success in calculus-based college mathematics, does not work for a large number of students. Moreover, even if it did work, the tools it provides are not those best suited to the quantitative needs of engaged citizens in our data-drenched society.

Some education and policy leaders are raising an even more fundamental question: Is this disconnect really a serious national problem that must be solved, or is it just the natural and benign result of using mathematics as the filter for access to successful careers? (Cynics, as usual, view the hype about assessments and underachievement as primarily an excuse for certain interest groups to make money-testing companies and textbook publishers come to mind.)

The most common argument for urgency is that education, especially in STEM disciplines, drives our economy. Yet contrarian economists argue that data from the past fifty years shows only a weak correlation between education and economy among nations or among states within the U.S. Many other issues (e.g., research, immigration, weather, infrastructure) dominate education as a predictor of economic growth. Moreover, some labor economists argue that the U.S. does not actually have a shortage of STEM-educated graduates or even of college graduates.

Nonetheless, parental pressure for college preparation remains high. Certainly a lot of the pressure for an algebra-centered curriculum leading to calculus is motivated by university admissions. Respondents to the Times op-eds express strong convictions on this point, most reflecting parental desire for traditional college-prep mathematics.

$$
* * * * *
$$

In thinking about these issues, it may help to pay some attention to the challenging puzzle of transfer. Virtually all STEM teachers recognize that students find it difficult to transfer skills taught in mathematics courses to the contextually rich problems encountered in other subjects. Transfer is required not only from mathematics to chemistry or economics but also to vocational areas such as nursing, plumbing, farming, or manufacturing. All require the use of mathematics in forms not typically seen in mathematics classes.

One important insight into the problem of transfer is summarized in a recent NRC report on education for life and work in the twenty-first century. ${ }^{11}$ This report emphasizes the importance of "transferable knowledge and skills" in contrast to "general skills" routinely used in civic, workplace, and family contexts.

General skills such as logical thinking are not, as is widely believed, a reliable consequence of the study of mathematics - or of anything else, for that matter. The NRC report is quite sweeping in this conclusion: "Over a century of research on transfer has yielded little evidence that teaching can develop general cognitive competencies that are transferable to any new discipline, problem or context, in or out of school" (italics added).

Many people, including many who wrote comments on the two Times op-eds, clearly do not believe this. (Ironically, the reasoning in many comments-trite emotional arguments that fail to address either the evidence or reasoning of each op-ed-seems to confirm the NRC conclusion.)

The difficulty students have in transferring skills from mathematics class to other subjects is well known and notorious among science teachers. Even changing $x$ to $t$ in equations of motion is enough to befuddle many students. More to the point, the difficulty of marshalling evidence and data into a persuasive written argument is not a natural consequence of the study of algebra or calculus-or of statistics, for that matter.

Both Times op-eds argue, with different particulars, for an approach to teaching mathematics that grows out of the contexts in which mathematics is used. The NRC report essentially reaffirms this approach. First, they define transferable knowledge and skills as "expertise that is intertwined with knowledge of a particular discipline" and go on to say that "teaching that emphasizes not only content knowledge, but also how, when, and why to apply this knowledge is essential to transfer" (italics added).

$$
* * * * *
$$

So we face three distinct challenges:

- Addressing the many weaknesses evident in mathematical learning.

- Reducing the gulf between the traditional precalculus curriculum and the quantitative needs of life, work, and citizenship.

- Teaching mathematics in a way that encourages transfer-for citizenship, for career, and for further study.

I suggest that these three challenges are manifestations of a single problem and that all three can be addressed in the same way: by organizing

\footnotetext{
$\overline{{ }^{11} \text { Education for Life and Work: Developing Transferable }}$ Knowledge and Skills in the Twenty-first Century, report brief, National Research Council, July 2012, http:// www7 . nationa1-academies.org/bota/Education_ for_Life_and_Work_report_brief.pdf
} 
the curriculum to pay greater attention to the goal of transferable knowledge and skills.

There are many ways to accomplish this, for example:

- by embedding mathematics in courses focused on applications of mathematics,

- by team-taught cross-disciplinary courses that blend mathematics with other subjects in which mathematical thinking arises (e.g., genetics, personal finance, medical technology),

- by project-focused curricula in which all school subjects are submerged into a class group project (e.g., design a solar-powered car),

- by career-focused curricula in which a cohort of students focuses all their school work on particular career areas (e.g., technology, communications, or business).

Each of these strategies has been employed in various school districts at different times, but they rarely spread "to scale", because they are typically more expensive in instructional effort and sometimes they appear to conflict with state standards or assessments. In principle-and if interpreted liberally-the new Common Core standards provide sufficient flexibility to permit approaches such as these. Unfortunately, experience with the relationship between standards, assessment, and instructional practices under NCLB (the 2001 No Child Left Behind Act) suggests that standards subjected to rigorous high-stakes tests will narrow instruction to focus as precisely as possible on topics and concepts needed to pass required tests.

Many worry that any approach motivated by applications rather than the structure of mathematics risks slighting some topics that would be found on any thoughtful list of standards. That's almost certainly true, because not every topic on these lists has natural uses outside mathematics itself. But the current approach virtually guarantees that large numbers of students will never learn (or at least not remember) these same rarely reinforced topics. So there may be little risk and much potential gain in trying a different approach.

$$
* * * * *
$$

The modern movement for standards in mathematics began in the 1980s when NCTM developed the first set of curriculum and evaluation standards for school mathematics. ${ }^{12}$ Compared with today's Common Core, this first set of standards is less specific, often less clear, in some respects less demanding, but in other aspects more challenging. But it also emerged in a different era and had a rather different purpose than does today's Common Core.

\footnotetext{
${ }^{12}$ Curriculum and Evaluation Standards for School Mathematics, National Council of Teachers of Mathematics, Reston, VA, 1989.
}

Today advocates view the setting of high standards and the establishment of measurable goals as a strategy for improving student performance. To be sure, even the most ardent supporters of the Common Core recognize that standards alone cannot achieve this goal. Significant improvement in the preparation and training of teachers is also essential. In particular, effective teaching of mathematics (and of other subjects) requires the kind of integrated understanding that has come to be called pedagogical content knowledge. ${ }^{13,14}$ Many also recognize that, since poverty is the strongest predictor of school failure, widespread progress is unlikely without difficult-to-achieve improvement in the socio-economic status of many students.

What we forget, however, is that when NCTM initiated its standards work, most mathematics teachers did not actually believe in the goal of teaching mathematics to all high school students. Whereas now we argue about how much and what kind of mathematics to teach in high school, three decades ago debate centered on who should learn high school mathematics. At that time, the curriculum was designed to efficiently sort students into those who were capable of learning high school mathematics and those who were not. So, between grades seven and nine, somewhere between onethird and one-half of the students were placed in a course called General Math, an enervating, pointless review of arithmetic.

One of the chief purposes-and chief accomplishments-of the 1989 Standards was to undermine the credibility of General Math by offering mathematics teachers and school administrators a vision of mathematics education of sufficient breadth, utility, and flexibility that it could be productively studied not just by prospective scientists and engineers but by virtually all students.

That ambitious undertaking largely succeeded. In the decade between the NCTM Standards and the NCLB Act, General Math was nearly eliminated from schools across the country. In its own way and without using these memorable words, NCTM's standards campaign opened the eyes of mathematics teachers to the "soft bigotry of low expectations."

Another decade has passed, and our ambitions are now much higher: a common core for all, with everyone emerging from high school ready for college. In one generation the political view of high school mathematics has progressed from something only some need (or can) learn to a core subject in which all students can and must become proficient. That's quite a rapid change in ends,

\footnotetext{
${ }^{13}$ Lee Shulman, "Knowledge and Teaching: Foundations of the New Reform", Harvard Educational Review 57 (1987), 1-22.

${ }^{14}$ Liping Ma, Knowing and Teaching Elementary Mathematics, Lawrence Erlbaum, Mahwah, N.J., 1999.
} 
which has been matched by a major change in means. The very idea of a common curriculum enforced with common assessments was all but unthinkable back in the 1980s.

Advocates of the Common Core often argue that, without a single high bar such as Algebra II for all, we will continue to leave poor and minority students behind. Too often, however, the bar itself leaves just as many students behind. In the 1980s the reason that half the students left high school without knowing any mathematics is that they never took any real mathematics courses while in high school. Today roughly the same proportion still leave school without confidence or skills in high school mathematics. But now the reason is very different: these students retain little or nothing of the mathematics they have been taught.

By itself, raising the bar won't change that. By privileging one type of ability over others, a single bar that is ratcheted up on the precalculus scale would quite likely increase the proportion of students whose educational experience creates dislike for mathematics. We don't seem to have learned much from the failure of NCLB to achieve its goals (remember "first in the world in math and science"?). In the next few years, as new assessments based on the Common Core are put in place with high-stakes consequences for students and teachers, we may simply see the same history repeated.
One respondent to Hacker's Times column cites management guru Peter Drucker as saying that society squanders vast resources encouraging people to eliminate their weaknesses. "We would be served better by accentuating their strengths." I wonder what would happen if we applied that philosophy to high school mathematics:

- It would require a different kind of standards document: one with significant content choices and explicit opportunities for project-based or interdisciplinary learning.

- It would tolerate-indeed, celebrate-a variety of strengths both within mathematics and in its uses, with the confidence that spot weaknesses could be remedied later whenever the need arose.

- It would virtually eliminate the possibility of uniform standardized assessments, which would not please politicians but would be welcomed by legions of teachers.

- And it would go a long way to addressing each of these current challenges:

- the persistent weakness in mathematics learning,

- the gap between high school mathematics and the QL needs of citizens,

- the inability of students to transfer skills from math class to other areas.

\section{Lie Algebra Sudoku}

A traditional Sudoku puzzle involves a $9 \times 9$ grid and the numbers 1 through 9. However, any set of nine symbols can be used. Through happy coincidence, there are nine complex simple Lie algebras: the four series of classical algebras and the five exceptional algebras. Therefor, it is possible to have a Sudoku puzzle using Lie algebras.

Instructions: Fill in the grid with complex simple Lie algebras so that each row and column and each highlighted $3 \times 3$ sub-grid contains each of the algebras $A_{n}, B_{n}, C_{n}, D_{n}, G_{2}, F_{4}$, $\mathrm{E}_{6}, \mathrm{E}_{7}$, and $\mathrm{E}_{8}$ without repeats.

-Puzzle by Edward Dunne

Solution on page 1473.

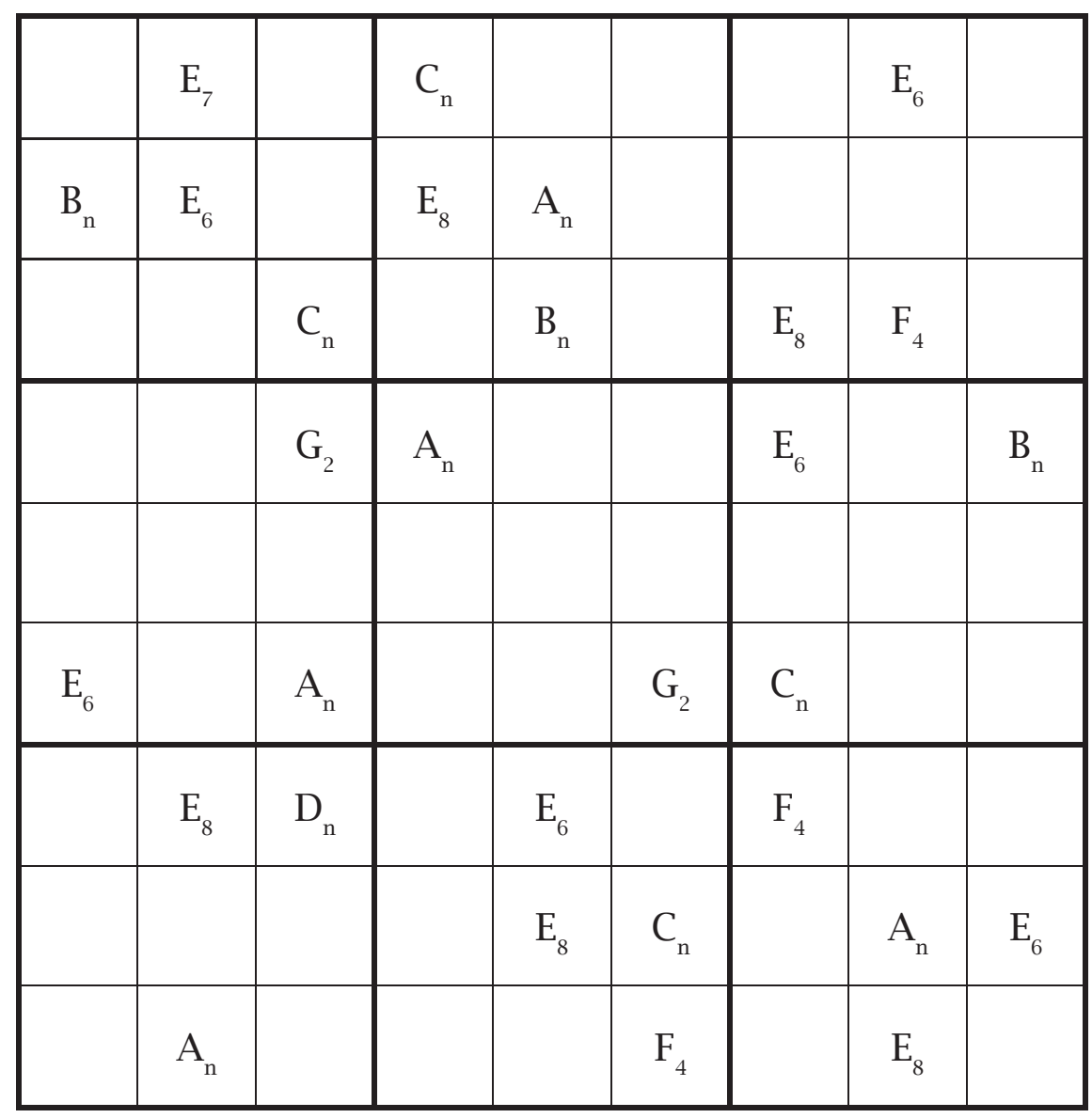

Notices OF THE AMS 